\title{
Utilizing the principles of Gagne's nine events of instruction in the teaching of Goldmann Applanation Tonometry
}

This article was published in the following Dove Press journal:

Advances in Medical Education and Practice

\section{Yee Ling Wong}

Ophthalmology Department, Ninewells Hospital and Medical School, Dundee, UK
Correspondence: Yee Ling Wong Ninewells Hospital and Medical School, 9 Pasteur Lane, DD2IUU, Dundee, UK Tel +447462856709 Email yeelingwong@nhs.net

\begin{abstract}
Intraocular pressure measurement is important to identify people who are at risk of glaucoma. Goldmann Applanation Tonometry is considered the gold standard with regards to evaluating patients with glaucoma, a sight-threatening condition. The professional execution of this evaluation is critical in the reduction of associated complication rates. This article seeks to put forward a structured lesson plan for ophthalmology trainees, specialist nurses, and optometrists, which integrates Gagne's nine events of instruction to accomplish this objective. Keywords: IOP, Gagne's model, lesson plan, Peyton's steps, glaucoma, ophthalmology teaching
\end{abstract}

\section{Introduction}

Tonometry is a diagnostic test that measures intraocular pressure (IOP), the fluid pressure inside the eye. It is important to measure IOP to identify people who are at risk of glaucoma, as people are often asymptomatic in the early stages. Early diagnosis can assist in the prevention of this potentially sight-threatening condition. Most tonometers are calibrated to measure IOP in millimeters of mercury ( $\mathrm{mmHg}$ ). There are a few types of tonometry currently available, with Goldmann Applanation Tonometry (GAT) considered to be the gold standard of tonometry. ${ }^{1,2}$ All adult patients being attended to at an eye unit should have their IOP measured unless there is a contraindication, such as corneal ulcer, present. ${ }^{3}$ While GAT is commonly used by a wide range of health care professionals including trained nurses and optometrists, it is essential to pay close attention to the procedural tasks to ensure patient safety as well as reduce the complications associated with this procedure. In this article, a lesson plan that incorporates Gagne's nine events of instruction to teach GAT within a small group teaching session is described. ${ }^{4}$

Gagne's nine events of instruction are as follows:

- Gaining attention

- Informing participants of objectives

- Stimulating recall of prior learning

- Presenting the content

- Providing learning guidance

- Eliciting performance

- Providing feedback

- Assessing performance

- Enhancing retention and transfer 


\section{Conditio sine qua (the prerequisites)}

Participants from various training levels and professions, such as allied health professionals, optometrists, and ophthalmology trainees, should be encouraged to attend these sessions. There should be an understanding of the basic anatomy and physiology of the eye. This session is designed with small group teaching in mind, which would provide a prime arena for the collaboration of ideas and knowledge within the group.

Prior to the GAT teaching session, pre-course reading material should be sent via email to the expected participants. Some of the areas that should be covered in this reading material are the risk factors and different types of glaucoma, indications for IOP measurement, applanation tonometry contraindications, and alternative methods of IOP measurement to be used when GAT is problematic. Additional reading resources may also be provided for those interested.

One of the most important considerations while using Gagne's model of instruction is to identify the learning outcomes to be achieved. ${ }^{4,5}$ In 1956, Bloom et al ${ }^{6}$ developed a framework for classifying educational goals and objectives into three main domains of educational objectives, namely, the cognitive, affective, and psychomotor domains. This framework was used to formulate the learning objectives, which are described below.

By the end of the session, participants should be able to

- understand the basic principles of a variety of applanation techniques;

- measure the IOP accurately using a Goldmann Applanation Tonometer;

- check the calibration of the tonometer correctly.

A lesson plan for GAT teaching is developed using the Gagne's events of instruction, and each of the events is illustrated in the subsections below.

\section{Gaining attention}

In order to facilitate audience assimilation of the content to be presented, gaining their attention is an essential step in the process of teaching. ${ }^{4}$ The theory of humanism postulates that the learning process is facilitated by basic physiological needs such as security and belongingness, that work in concert to reach goal attainment and self-actualization for the individual. ${ }^{7}$ To ensure that participants are ready to learn and participate, the session commences with a group activity designed to allow the members to interact and establish relationships with one another and minimize the sense of being in an unfamiliar learning environment. This encourages participants to engage with the presenter and each other, as well as ask questions and exchange ideas. Sticky labels are used as aids to help participants learn the names of other members in the session to promote intragroup cohesion and camaraderie.

A "thought-provoking" stimulus should be used as a device to gain the participants' attention. Attendants should also be encouraged to pose questions that will be opened to other students in the session to answer. Questions posed should be related to the pre-course materials, for example, "In what situations would Goldmann Applanation Tonometry be inappropriate?" This approach allows participants to learn from their interaction with other participants. ${ }^{8,11}$

Following this, a short video clip of applanation tonometry in action is presented and sticky notes are distributed to each participant. The participants are then tasked to write down the one good and one bad (performance-wise) point they noticed in the video clip. These sticky notes will then be collected and, later on in the session, discussed. The combination of activities, thought-provoking questions, and short video clips is intended to stimulate a variety of sensory cues to improve information retention of the participants. In addition, these activities accommodate all the four modalities of learning styles as suggested by Fleming and Mills (1992). ${ }^{5,9}$

\section{Inform students of the objectives}

After the introduction, participants are apprised of the learning objectives to aid their learning process. These objectives intend to list the skills and proficiencies the participants will hopefully be able to achieve after the session (Adam, 2004). ${ }^{10}$ Participants are given ample opportunities to ask questions with relation to the learning objectives to help them understand what they are learning and to ensure that they are cognizant of the objectives. ${ }^{5-12}$

\section{Stimulate recall of prior learning}

It is vital to assimilate prior experience and personal experiences when dealing with new information. As Gagne et al $(1988)^{13}$ suggest, previously acquired knowledge must be accessible during the process of the current learning event. This helps to facilitate the learning process by allowing participants to integrate this new learning into their own reality by interpreting it based on their previous experiences, beliefs, and mental structures (Good and Brophy, 1990). ${ }^{14,15}$

In this session, some participants may have prior working experience with GAT due to the inter-professional nature of the class, which they will be encouraged to share. Those 
without prior experience will then be able to benefit from the experiences of others. ${ }^{8,11}$

From the sticky notes with the participant's perspectives on the short video clip presented earlier, the comments will be transferred onto a flipchart with the good points on one column and the bad points on another. This is followed by an open discussion to encourage participants to share their thoughts and foster the development of interpersonal and intrapersonal intelligences. ${ }^{16}$

\section{Presenting the content}

A detailed explanatory PowerPoint presentation about GAT is used to present the content to the participants. Topics covered in this presentation include a comprehensive introduction to the equipment used, the preparation necessary for the procedure, and finally, a step-by-step method to measuring IOP using GAT. ${ }^{3}$ A summary flowchart of the steps is provided as a handout. Participants are also presented with a variety of commonly used tonometers including the applanation tonometer and the Perkins tonometer to stimulate their kinaesthetic and visual learning cues. Finally, on the basis of Peyton four-step approach for practical skills teaching (demonstrate-deconstruct-comprehend-perform), ${ }^{17,18}$ there follows a demonstration of the actual procedure at a normal pace without any explanation.

\section{Providing learning guidance}

As the session progresses, the different parts of an applanation tonometer and the method of calibration of the tonometer will be discussed. Before proceeding on to explaining each of the steps to measure IOP via GAT, participants will be provided a procedural checklist (Figure 1), so that they will be able to focus on establishing competency in the specified areas. These areas include hygiene, patient safety, equipment gathering, tonometry procedure (illumination, applanation, measurement), interpretation of results, and finally, an overall professionalism when performing the procedure. The procedure is then performed again, but this time with a full explanation of each step and practical tips on the use of GAT. Participants are encouraged to ask questions and take notes for future reference to allow for better comprehension of the practical procedure taught.

\section{Eliciting performance}

In order to ensure that the participants continue to be in a state of mind conducive to learning and to restore their endurance, a short "coffee break" should be allowed for, before moving on to the next task. This next task is a major part of this learning session, and it involves allowing the participants to learn through performing the procedure themselves. The participants should be split into groups of three, taking turns to "assess" (using the same procedural checklist), to "perform" (IOP measurement), and be "examined" (as a simulated patient) under careful supervision. By experiencing all three roles, participants will gain more insight into the procedure, enhancing their learning process.

\section{Providing feedback}

Feedback is important because it allows participants to maximize their potential by affording them a chance to be aware of their strengths and weaknesses, allowing them to identify actions to be taken to improve their performance. It is central to developing learner's confidence and competence. While participants are performing GAT, they are provided with immediate feedback to allow them to clarify any uncertainties that may arise. Timely feedback is essential for a good learning process and to foster good clinical practices. ${ }^{19}$ Additionally, observers should be encouraged to incorporate the feedback provided.

The "Ask-Tell-Ask" feedback model is used to foster participants' abilities to identify their own strengths and weaknesses. It also provides the opportunity to share positive and constructive feedback to students. This feedback model is learner-centered, and helps to improve their self-assessment skills as well as gives insight into the participants' perceptions of their performance. ${ }^{19}$ It is very versatile and can also be used in a variety of settings.

- ASK: Ask participants to assess their own performance. Begin a conversation to assess learner's level of insight. React to learner's observation.

- TELL: Tell what you observed using positive and constructive methods. Use specific behaviors without judgment.

- ASK: Ask about learner's understanding and strategies for improvement. Close by committing to an action plan.

\section{Assessing performance}

Following the practice session, participants will be required to demonstrate their procedural skills. They will be assessed on how they approach the patient, their communication skills, and their overall performance. The assessment checklist (Figure 1) is used to grade the participants and is also a platform for feedback from the instructor and contains a comment box.

The participants should reflect on the feedback provided and compare them to their own self-evaluation to identify points to improve on and formulate personal actions plans to further their proficiency. 
Name:

Date:

Tutor:

\begin{tabular}{|c|c|c|c|c|}
\hline & Excellent & Good & $\begin{array}{c}\text { Pass } \\
\checkmark\end{array}$ & $\begin{array}{c}\text { Fail } \\
x\end{array}$ \\
\hline $\begin{array}{l}\text { Approach: } \\
\text { Introduces self } \\
\text { Explains procedure and gain consent } \\
\text { Remind patients to breathe normally throughout the } \\
\text { procedure (breath-holding will falsely elevate the IOP) }\end{array}$ & & & & \\
\hline $\begin{array}{l}\text { Hygiene: } \\
\text { Washes hand } \\
\text { Equipment cleaning and handling }\end{array}$ & & & & \\
\hline $\begin{array}{l}\text { Assess risks: } \\
\text { Risk factors for glaucoma } \\
\text { Previous adverse reactions to topical drops } \\
\text { Cautious of contraindications i.e. corneal abrasion }\end{array}$ & & & & \\
\hline $\begin{array}{l}\text { Equipment handling: } \\
\text { Handle and assemble equipment appropriately before } \\
\text { carrying out procedure }\end{array}$ & & & & \\
\hline $\begin{array}{l}\text { Tonometry (illumination): } \\
\text { Angle } \\
\text { Brightness } \\
\text { Beam }\end{array}$ & & & & \\
\hline $\begin{array}{l}\text { Tonometry (applanation): } \\
\text { Central applanation } \\
\text { Changes force on the cornea }\end{array}$ & & & & \\
\hline $\begin{array}{l}\text { Tonometry (measurement): } \\
\text { Good mires } \\
\text { Endpoint of rings touching }\end{array}$ & & & & \\
\hline $\begin{array}{l}\text { Interpret results: } \\
\text { Accuracy } \\
\text { Recommendations for management and follow-up }\end{array}$ & & & & \\
\hline $\begin{array}{l}\text { Overall professionalism: } \\
\text { Communication } \\
\text { Patient safety }\end{array}$ & & & & \\
\hline $\begin{array}{l}\text { Simulated patient score: } \\
\text { General impression }\end{array}$ & & & & \\
\hline
\end{tabular}

Additional comments:

Figure I Procedural checklist: Goldmann Applanation Tonometry.

Abbreviation: IOP, intraocular pressure.

\section{Enhancing retention and transfer}

In this section, real glaucoma patients who volunteered beforehand to be examined by the participants will make their entrance. These patients have various abnormal IOPs and will be given the opportunity to give feedback about their experience to participants after they have examined them. As a result, participants will be able to utilize their newly acquired skills in clinical practice and make sense of 
their learning session. ${ }^{4}$ Participants are then encouraged to discuss among each other about their learning achievements and also things to be improved. The session is concluded by summarizing the learning objectives and by answering the remaining questions the participants may have.

\section{Discussion}

Despite being the gold standard for IOP measurement, GAT does have its disadvantages. Testing is limited to certain areas where slit lamps are readily available, as this procedure requires a slit lamp to perform. GAT is also limited by the need of a skilled examiner and also the portability of the instrument. ${ }^{20-22}$ In addition, contacting the surface of the cornea predisposes the eye to a risk of infection, especially in the early postoperative period or in those with corneal abrasions or ulcers. ${ }^{20}$ Most importantly, its use is limited in young children and in patients with physical disability who cannot be positioned properly on a slit lamp. ${ }^{18}$ In order to eliminate these disadvantages, various alternative instruments can be used. One example is the ICare rebound tonometer, which does not require either a slit lamp biomicroscopy or anesthetic drops, as the force applied is minimal. It is easy to use, portable, and the results are highly reproducible. ${ }^{23}$ Another instrument is the Perkins tonometer, which can be used for patients who are unable to sit forward on a slit lamp. Nonetheless, it requires topical anesthetic drops. ${ }^{20-23}$ Non-contact tonometry, on the other hand, does not require topical anesthesia and can be used safely in postoperative cases, as the risk of infection is minimal. ${ }^{20}$

The current practical skills teaching of GAT in mainstream institutions, like most practical skills teaching, involves a pre-course reading material, a tutorial relating to IOP measurement, and finally, practice of the practical skill itself. The majority of the ophthalmology skills sessions involve pairing up with another participant, and this is often supervised by one or two skilled supervisors.

The Gagne's nine events of instruction cater to a plethora of different learning styles and help to facilitate the learning process substantially. It is superior by far to the current practice of GAT teaching. This lesson plan allows participants from various levels of training to be involved. It is not limited to participants who have had practical and theoretical experience of GAT and can also be applied to those without prior experience of GAT. Hence, practitioners who are not confident with GAT can also benefit from the described learning plan. This also encourages the exchange of ideas between members of the multidisciplinary team. The current practice of GAT requires that skills are performed repeatedly following a teaching session to acquire it. However, this lesson plan ensures that knowledge and skills are consolidated before the end of the session. Discussion is also encouraged to allow full understanding of the procedure taught.

While giving feedback, participants are required to be ready and willing to accept feedback and criticisms, as well as to have a certain degree of self-awareness and insight to their performance. The Ask-Tell-Ask feedback model is a good way to allow participants autonomy to identify their strengths and weaknesses.

In addition to feedback provision, a self-assessment tool (Figure 2) should be filled in by the facilitators of the session to encourage them to reflect on their own teaching and to ensure that teaching is optimal.

\section{Limitations}

However, this lesson plan does have some limitations. When undertaking a lesson with a small group, additional resources such as administration time, facilitators, and rooms may be required. Different facilitators have different teaching styles and behavior, and it is difficult to predict whether these facilitators will be able to assist participants to achieve the expected learning outcomes completely. Some tutors may even potentially negatively impact the participants' selfefficacy and motivation. This risk can be minimized by a having a briefing and debriefing session to ensure consistency of outcome delivery. Participants should also be encouraged to give feedback on tutors to ensure that the quality of teaching is optimal.

Also, due to the nature of the session, participants may ask questions that stray away from the learning outcomes. A way of ameliorating this is by establishing ground rules at the start of the session, or by asking tutors to be aware of the learning outcomes at all times and attempt to steer the conversation back into relevant topics.

Another limitation is the involvement of volunteer patients in this practical session. Although this allows enhancement of skills transferable to real-life situations, it may be impractical due to the potential consequences of this procedure, such as the risk of a corneal abrasion. This activity also depends on the availability of willing glaucoma patients, which is variable. It would be safer and more reliable to practice on an eye model designed for teaching applanation tonometry.

\section{Conclusion}

The Gagne's nine events of instruction cater to different learning styles and help to facilitate the learning process. It 
Date:

Trainer:

\begin{tabular}{|c|c|c|c|c|c|c|}
\hline Items & $\begin{array}{r}\text { Plea } \\
1\end{array}$ & ate & rse & $\mathbf{a}$ & & Reflection \\
\hline Preparation & 1 & 2 & 3 & 4 & 5 & \\
\hline Introduction and warm-up & 1 & 2 & 3 & 4 & 5 & \\
\hline $\begin{array}{l}\text { Inform participants of the aims and } \\
\text { objectives }\end{array}$ & 1 & 2 & 3 & 4 & 5 & \\
\hline Presentation & 1 & 2 & 3 & 4 & 5 & \\
\hline $\begin{array}{l}\text { Appropriate use of methods and } \\
\text { materials }\end{array}$ & 1 & 2 & 3 & 4 & 5 & \\
\hline Checks understanding & 1 & 2 & 3 & 4 & 5 & \\
\hline $\begin{array}{l}\text { Provide clear explanation and } \\
\text { clarify uncertainties }\end{array}$ & 1 & 2 & 3 & 4 & 5 & \\
\hline Ensure participation & 1 & 2 & 3 & 4 & 5 & \\
\hline Provide timely feedback & 1 & 2 & 3 & 4 & 5 & \\
\hline Contact and follow-up & 1 & 2 & 3 & 4 & 5 & \\
\hline Time allocation and facilitation & 1 & 2 & 3 & 4 & 5 & \\
\hline
\end{tabular}

Figure 2 Trainer self-assessment Goldmann Applanation Tonometry.

provides a structured approach to formulating a lesson plan that is applicable to many other practical skills.

\section{Acknowledgment}

I would like to express thanks to Kevyn Lim Zi Rong for proofreading.

\section{Disclosure}

The author reports no conflicts of interest in this work.

\section{References}

1. Schlote T, Landenberger H. Augeninnendruckmessung mit dem transpalpebralen Tonometer TGDc-01,PRA” im Vergleich zur Applanationstonometrie nach Goldmann bei Glaukompatienten [Intraocular pressure difference in Goldmann applanation tonometry versus a transpalpebral tonometer TGDc-01 "PRA" in glaucoma patients]. Klin Monbl Augenheilkd. 2015;222(2):123-131. German.

2. Amm M, Hedderich J. [Transpalpebral tonometry with a digital tonometer in healthy eyes and after penetrating keratoplasty]. Ophthalmologe. 2005;102(1):70-76. German.
3. Stevens S, Gilbert C, Astbury N. How to measure intraocular pressure: applanation tonometry. Community Eye Health. 2007;20(64):74-75.

4. Gagne RM, Wager WW, Golas KG, Keller JM. Principles of Instructional Design. 5th ed. Mason, OH: South-Western; 2005.

5. Ng JY. Combining Peyton's four-step approach and Gagne's instructional model in teaching slit-lamp examination. Perspect Med Educ. 2014;3(6):480-485.

6. Bloom, B. S., Engelhart, M. D., Furst, E. J., Hill, W. H., \& Krathwohl, D. R. (1956). Taxonomy of educational objectives: The classification of educational goals - Handbook I, cognitive domain. New York, NY: David McKay.

7. Maslow AH. A theory of human motivation. Psychol Rev. 1943;50(4): 370-396.

8. Vygotsky LS. Mind in Society: The Development of Higher Mental Process. Harvard University Press; 1978.

9. Fleming ND, Mills C. Not another inventory, rather a catalyst for reflection. From To Improve the Academy. 1992 11:137-155. Available from: http://digitalcommons.unl.edu/cgi/viewcontent.cgi?article=1245\&con text=podimproveacad. Accessed August 26, 2017.

10. Adam S, 2004, Using Learning Outcomes: A consideration of the nature, role, application and implications for European education of employing 'learning outcomes' at the local, national and international levels. United Kingdom Bologna Seminar 1-2 July 2004, Heriot-Watt University (Edinburgh Conference Centre) Edinburgh. Scotland. 
11. Tofade T, Elsner J, Haines ST. Best practice strategies for effective use of questions as a teaching tool. Am J Pharm Educ. 2013;77(7):155.

12. Buscombe C. Using Gagne's theory to teach procedural skills. Clin Teach. 2013;10(5):302-307.

13. Gagné RM, Driscoll MP. (1988). Essentials of learning for instruction (2nd ed.). Englewood Cliffs, NJ: Prentice-Hall, Inc.

14. Merrill MD. Constructivism and instructional design. Educ Technol Soc. 1991;31(5):45-53.

15. Good TL, Brophy JE. (1990). Educational psychology: A realistic approach. (4th ed.). White Plains, NY: Longman

16. Woo WH. Using Gagne's instructional model in phlebotomy education. Adv Med Educ Pract. 2016;7:511-516.

17. Nikendei C, Huber J, Stiepak J, et al. Modification of Peyton's four-step approach for small group teaching - a descriptive study. BMC Med Educ. 2014;14:68.

18. The Peyton R, Cycle Learning. Teaching and Learning in Medical Practice. Rickmansworth, UK: Manticore Europe Limited; 1998.
19. Ramani S, Krackov SK. Twelve tips for giving feedback effectively in the clinical environment. Med Teach. 2012;34(10):787-791.

20. Mohan S, Tiwari S, Jain A, Gupta J, Sachan SK. Clinical comparison of Pulsair non-contact tonometer and Goldmann applanation tonometer in Indian population. J Optom. 2014;7(2):86-90.

21. Evans K, Wishart PK. Intraocular pressure measurement in children using the Keeler Pulsair tonometer. Ophthalmic Physiol Opt. 1992;12(3): 287-290.

22. dos Santos MG, Makk S, Berghold A, Eckhard M, Haas A. Intraocular pressure difference in Goldmann applanation tonometry versus Perkins hand-held applanation tonometry in overweight patients. Ophthalmology. 1998;105(12):2260-2263.

23. Catagay HH, Ekinci M, Yazar Z, Gokce G, Ceylan E. Comparison of ICare rebound tonometer and Goldmann applanation tonometer in high myopia. Sci World J. 2014;2014:869460.
Advances in Medical Education and Practice

\section{Publish your work in this journal}

Advances in Medical Education and Practice is an international, peerreviewed, open access journal that aims to present and publish research on Medical Education covering medical, dental, nursing and allied health care professional education. The journal covers undergraduate education, postgraduate training and continuing medical education

\section{Dovepress}

including emerging trends and innovative models linking education, research, and health care services. The manuscript management system is completely online and includes a very quick and fair peer-review system. Visit http://www.dovepress.com/testimonials.php to read real quotes from published authors.

Submit your manuscript here: http://www.dovepress.com/advances-in-medical-education-and-practice-journal 